International Journal of Engineering \& Technology, $7(2)(2018) 621-625$
International Journal of Engineering \& Technology
SPC
Website: www.sciencepubco.com/index.php/IJET
doi: $10.14419 /$ ijet. $v 72.10239$
Research paper

\title{
Design and construction of a prototype vertical axis wind turbine (VAWT) for battery charging application
}

\author{
Sunil Thomas ${ }^{1}$ *, Mohammed Ashar Riyan Khan ${ }^{2}$, A B Chattopadhyay ${ }^{3}$ \\ ${ }^{1,3}$ Department of Electrical and Electronics Engineering, Birla Institute of Technology and Science, \\ Pilani, Dubai, United Arab Emirates \\ ${ }^{2}$ Department of Electronics and Instrumentation Engineering, Birla Institute of Technology and Science, \\ Pilani, Dubai, United Arab Emirates \\ *Corresponding author E-mail: sunil.thomasp@gmail.com
}

\begin{abstract}
One of the major issues in this fast moving world is to meet the demand of energy in the most economical and environment friendly way. This research work on designing of a Vertical-axis wind turbines(VAWT) that gives a solution which is comparatively a cheap alternative of renewable energy. The Windmill rotates with sufficient wind, causing it to generate electricity owing to magnetic coupling between the rotating and stationary coil. The work demonstrates a vertical rotating prototype of windmill. The wind turbine can charge up to $12 \mathrm{~V}$ battery. Advantage of this design is that it works without any consumption of fossil fuel and works efficiently in appropriate weather conditions without being closely monitored and the battery charges automatically without any harmful emissions or drawbacks. The work presented in this paper is an example of how natural resources like the wind energy can be used efficiently to produce electricity.
\end{abstract}

Keywords: Battery Charging; Renewable Energy; Wind Turbine; VAWT.

\section{Introduction}

The demand for electrical energy is increasing exponentially and relaying on fossil fuel resources will pose a threat to the humankind as the availability of these resources are getting limited. Hence the focus should be on the renewable energy sources such as solar, wind, tidal etc [1]. These sources have been coined renewable due to their continuous replenishment and availability for use over and over again. The popularity of renewable energy has experienced a significant upsurge in recent times due to the exhaustion of conventional power generation methods and increasing realization of its adverse effects on the environment. This popularity has been bolstered by cutting edge research and ground breaking technology that has been introduced so far to aid in the effective tapping of these natural resources and it is estimated that renewable sources might contribute about $20 \%$ $50 \%$ to energy consumption in the latter part of the 21 st century. Facts from the World Wind Energy Association estimates that by $2010,160 \mathrm{GW}$ of wind power capacity is expected to be installed worldwide which implies an anticipated net growth rate of more than $21 \%$ per year[2]. The main advantage considering the renewable energy source as a main stream source for energy generation is that they are clean, non-polluting to the environment and its abundance. Although wind has been harnessed for centuries, it has only emerged as a major part of our energy solution quite recently. Before the 21 st century, wind was primarily used to pump water from wells and to grind grain, but over the last twenty years the cost of wind energy has dropped by more than 80 percent, turning it into the most affordable form of clean energy. Recent advances have allowed for sophisticated wind technologies, which previously sat in the mind of thoughtful engineers and inventers, to be developed into cost-effective, reliable solutions. For a small wind turbine to be effective, it must produce energy across a wide range of wind speeds. It must be able to generate energy from winds that are switching directions and gusting. It must also be very quiet, so that it will not disturb people living nearby, and it certainly helps if it is pleasing to the eye as well. Wind power harnesses the power of the wind to propel the blades of wind turbines. These turbines cause the rotation of magnets, which creates electricity. Wind towers are usually built together on wind farms.

\section{Related work}

A detailed analysis and methodology to improve the efficiency of horizontal axis wind turbines (HAWT) has been detail explained in [3], [4]. However vertical axis wind turbines (VAWT) have gained its popularity and the counter rotating mechanism and its recent advancements are reported in [5], [6]. There has been lot of research advancements in the area of VAWT since 1980. Ishimatsu et al [7] has done a critical study and a 2D simulation of darrius turbine was carried out. The major advantages and disadvantages of HAWT and VAWT has been explicitly described and is available in the literature [8]. A recent and novel idea of magnetically levitated Vertical Axis Wind Turbine [9] draws attention of many researchers working in this area. The operational part and its associated difficulties are clearly explained in a detail manner in [10]. Comparison of performance in vertical axis and horizontal axis wind turbines to get optimum power output is found in literature[11] and the results tabulated gives a clear idea on the maximum speed attained and the corresponding power output obtained Similar works on other performance parameters of VAWT has also been reported in [12], [13]. Another interesting work on float- 
ing vertical axis wind turbine has been presented in [14]. The work reported in [15] provides convincing simulation results on the performance study for vertical axis wind turbine. An overview of characterization of the VAWT has been reported in [16]. B Hand et.al [17] has come up with a low-order model that can be utilized for the aerodynamic modeling. A similar work which proposes a charge controller design based on Arduino-mega chip for a hybrid renewable energy system is proposed in [18]. This works proposes a comparison between hybrid system employs a microcontroller to ensure the finest utilization of resources and hence improving the overall efficiency, as compared with their individual mode of generation, under varying climatic conditions without measuring the irradiance on the photovoltaic panels or the wind speed, using pulse width modulation control technique.

All the above literature review reveals that the design and usage of VAWT is gaining importance and in this work we intend to present a VAWT design which is simple and practically feasible to manufacture and use in small and medium applications. The smallest turbines are used for applications such as battery charging or auxiliary power on sailing boats; while large grid-connected arrays of turbines are becoming an increasingly large source of commercial electric power. The motivation behind the present research paper lies in the fact that a low speed of wind can be utilized or not for a small (or, medium) application using a proper transducer or controller.

This research paper demonstrates a vertical axis wind turbine which is connected to a 500 RPM $12 \mathrm{~V}$ DC motors with metal gearbox.The work flow and design details are presented in the subsequent sections.

\section{Problem formulation}

The basic principle on which the problem formulated can be explained from the Figure. 1

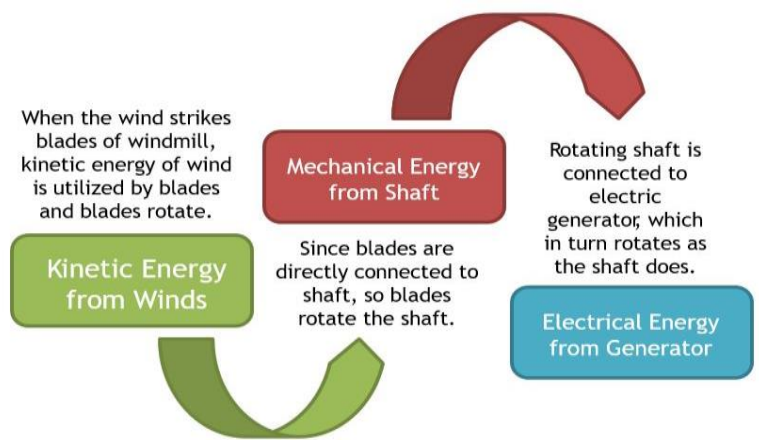

Fig. 1: Basic Design Concept (Wind Power Generation).

A windmill converts wind energy into rotational energy by the use of blades. The blades of a windmill are aerodynamically optimised to make the most of the energy in the wind and turn it into rotational energy - making the blades spin around. The windmill is designed with number of variations in the blade and the windmill designed for this research work has 5 blades. These blades are connected to a generator through a gearbox which in turn rotates the shafts, the generator converts mechanical energy which is the rotation of the blades into electrical energy. Once the electricity is generated, and can be made suitable to enter the local grid, from where it can be used as power. Some windmills are controlled by computers. One of the main function is to keep the windmill facing the wind. To do this the computer monitors the direction and speed of the wind using instruments on top of the windmill. With this data the 'hub' of the windmill is kept turned so that the blades are always facing into the wind. According to the wind circumstances the blade twist or shred the wind. It is well known that proper shaping of the blades of a windmill and the proper alignment of the physical axis of that mill influences to a large extent the efficiency of the said mechanical converter to convert the 'raw' wind power to a considerable value of rotational energy offered by the blades of the mill. Therefore based on this view point a proper 3 -D design of the wind turbine is suggested and it is discussed with detailed design views in the next section.

\subsection{Wind turbine 3D design}

Solid works ds 3 has been used in this work for the simulation and development of the Vertical Axis Wind Turbine.

The different projections of the design are presented in Fig. 2 (a), (b) and (c).

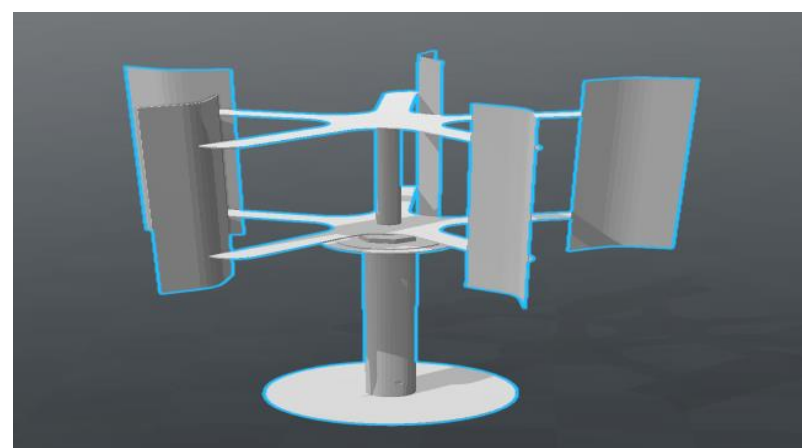

Fig. 2: A) Wind Turbine 3D Design (Solid Works Ds3) All the Dimensions are Accurate Up to $2 \mathrm{Mm}$ of the Real Model.

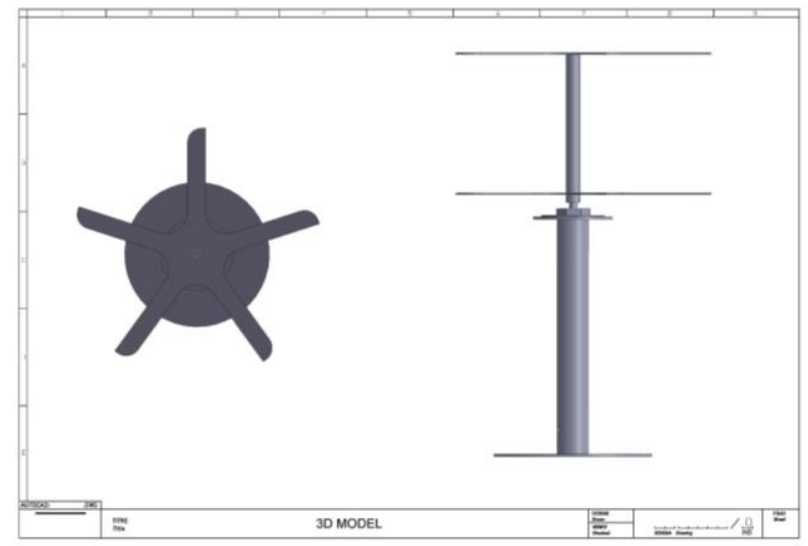

Fig. 2: B) Top and Front View of the Wind Turbine 3D Design (Solid Works Ds3) All the Dimensions are Accurate Up to $2 \mathrm{Mm}$ of the Real Model.

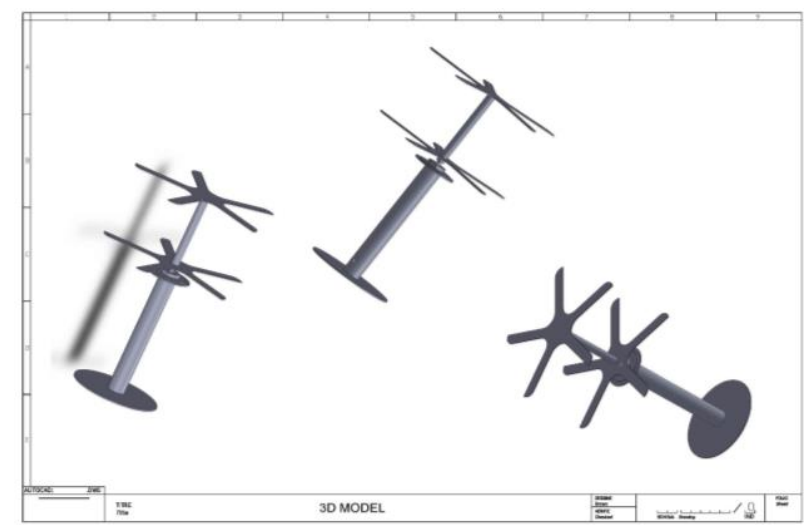

Fig. 2: C) Isometric View of the Wind Turbine 3D Design (Solid Works Ds3) All the Dimensions are Accurate Up to $2 \mathrm{Mm}$ of the Real Model.

\subsection{VAWT component selection}

The whole concept of material selection for the manufacturing of the wind turbine lies in the following facts:

i) The fabricated structure should be robust and mechanically strong.

ii) Blades should be light in weight 
iii) The materials used inside the generator must consists (partially) electrically conductive materials (metals).

Based on the above said factors, aPIE-CHART design of the composition of different materials is presented in Fig.3

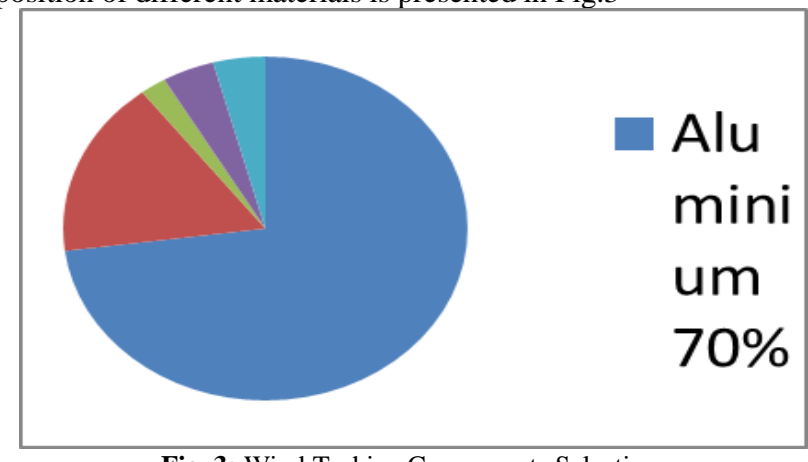

Fig. 3: Wind Turbine Components Selection.

Different Types of materials have been selected based on their physical properties and structural rigidity. As structural strength is most important for greater efficiency and smooth power production. Table 1 is hereby presented showing the distribution of different types of metals in the whole mechanical structure of the proposed wind turbine A 500 RPM $12 \mathrm{~V}$ dc generator with metal gearbox has been used. The gear box has Shaft Diameter of $6 \mathrm{~mm}$. The No-

Table 1: Components versus Percentage Total Mass of the Design

\begin{tabular}{llll}
\hline Component & Item & Material & $\begin{array}{l}\text { Percentage of total } \\
\text { mass }\end{array}$ \\
\hline Tower and Base & Frame \& & Steel & $40 \%$ \\
Nacelle & Sheet metal & $25 \%$ \\
& Generator & Steel & $15 \%$ \\
& & Copper & $2 \%$ \\
Rotors & Blades & Sheet metal & $4 \%$ \\
& Hub and & Aluminium & $1 \%$ \\
& bolts & Steel & $1 \%$ \\
\hline
\end{tabular}

Load Current is 1 Ampere (Max) with a Torque of $2 \mathrm{Kg}$-cm which has been placed inside the Vertical Tower Directly attached to the rotating blades of the VAWT. A Lead Acid Sealed (SLA Battery) with $12 \mathrm{~V} \mathrm{DC}, 1.2 \mathrm{Ah}$ has been used in the prototype. The efficiency under ideal condition of the battery is $86 \%$.

\subsection{Prototype development}

The basic block diagram of the prototype of the said energy converter is shown in Fig.4. In Fig.4, the de generator is basically shown as a part of the windmill structure. The microcontroller has been designed using the chip, ATMEGA 328 which has been shown in Fig.5. The microcontroller must be powered from a suitable power supply source which acts as a control element of the circuit design. The power supply and associated components like the rectifier, voltage regulator and the display unit are connected to the micro controller. The output of the said controller ultimately charges the battery.

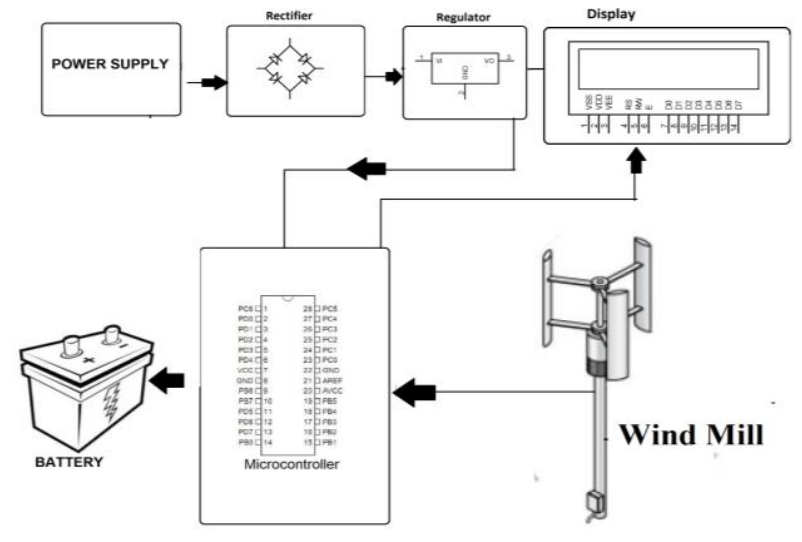

Fig. 4: Block Diagram of the Proposed System Design.

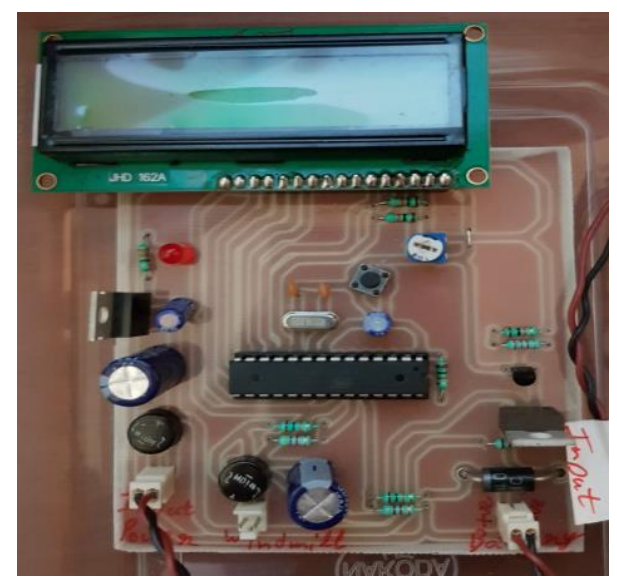

Fig. 5: Charge Controller Design Using ATMEGA 328

The actual laboratory arrangement for the experimental process of charging a battery or mobile phone is presented in Fig 6 .

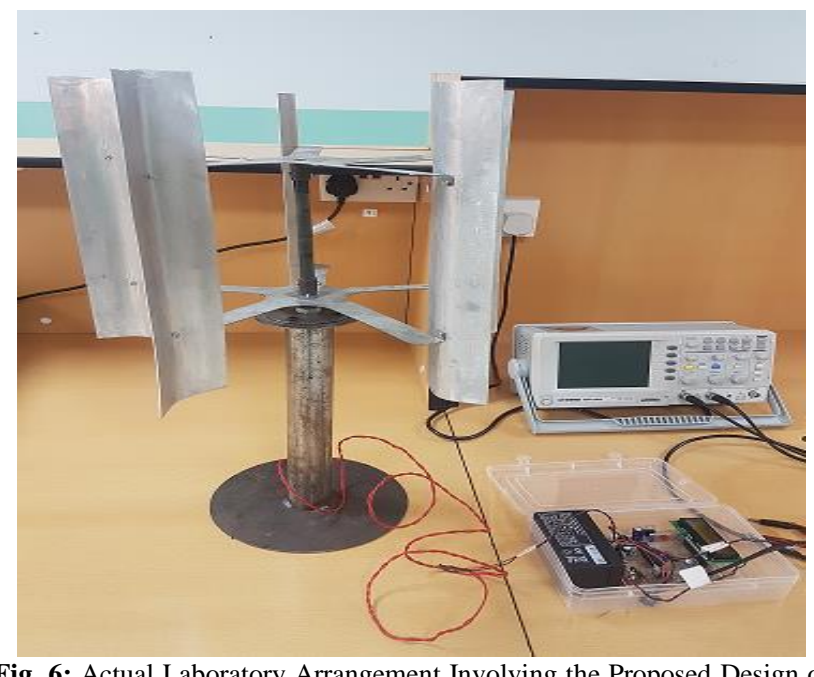

Fig. 6: Actual Laboratory Arrangement Involving the Proposed Design of VAWT.

Logically any "Problem Formulation" section must include a relevant mathematical model. Based on this concept, a mathematical model of the power contained in "air" is presented in the next section to have a better feeling on the simulated and the experimental results.

\subsection{Mathematical model for power contained in air}

The kinetic energy due to the motion of the wind is the source of power in the design. Therefore the power contained due to kinetic energy can be written as 


$$
k=\frac{1}{2} m v^{2}
$$

Where $\mathrm{k}=$ time derivative of kinetic energy

The volume of air passing in unit time through an area 'a', with velocity ' $v$ ' is 'Av' ad its mass is equal to the volume ' $\mathrm{V}$ ' multiplied by its density ' $\rho$ '. i. e,

$\mathrm{m}=\rho \mathrm{V}$, which is in $\mathrm{kg} / \mathrm{sec}$

Substituting equation (2) in (1) it yields ,

$$
k=\frac{1}{2}\left(\rho a v^{3}\right)
$$

To convert the energy obtained to kilowatts non-dimensional proportionality constant ' $\mathrm{k}$ ' is introduced, where $\mathrm{k}=2.14 * 10^{-3}$

Power in kilowatts $(\mathrm{P})=2.14 \rho a v^{3} * 10^{-3}$

Air density $\rho=1.2 \mathrm{~kg} / \mathrm{m}^{3} / 2.33 * 10^{-3}$ slugs $/ \mathrm{ft}^{3}$

Based on the above said mathematical treatment, simulated results have been presented in the next section.

\section{Results and discussions}

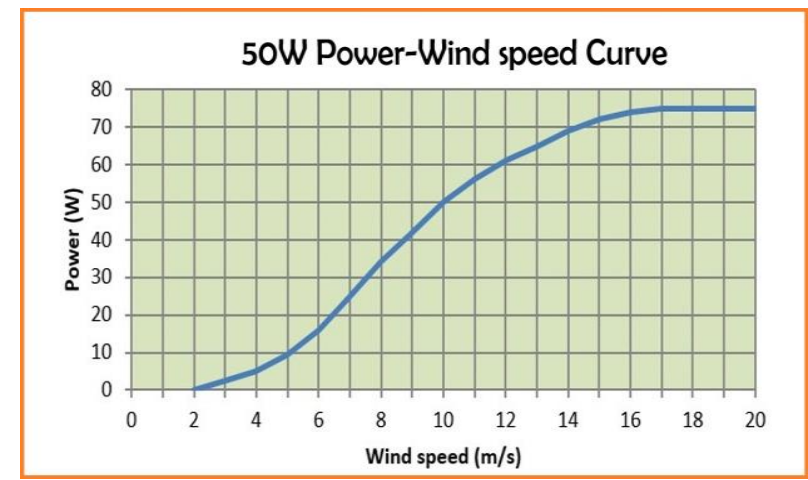

Fig. 7: Designed Power-Wind Speed Curve.

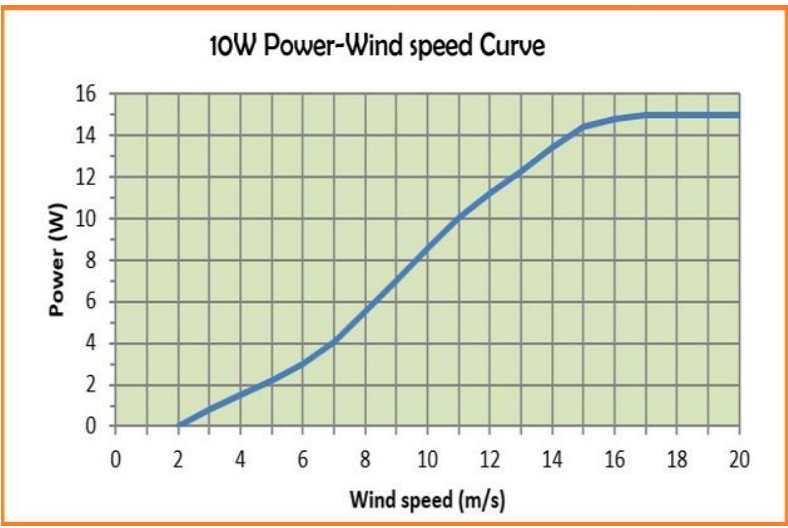

Fig. 8: Achieved Power-Wind Speed Curve.

The simulated results shows a comparison between the designed and the achieved power for a specific range of wind velocity. However due to losses, lack of constant velocity of wind, we were able to achieve less than the designed value.

The device generates $3-12 \mathrm{~V}$ potential difference with the wind energy. The study shows that there is great potential in wind energy to generate power. A careful selection has to be made for the blade profile so that the losses will be minimum and the power generation can be enhanced. Since the wind energy is not constant at all the time so the operation of the wind machine will be intermittent and the power production rate will also vary; the component selected in the proposed design is in such a manner so that the losses will be at a minimum. Furthermore the results confirm that the mobile charging is not getting disturbed even at low speed of wind

The results obtained in this proposed work has been compared with an existing work[18].The same has been tabulated as follows:

Table 2: Conventional Prototype V/S Proposed Prototype in Terms of Speed V/S Power Output

\begin{tabular}{lllll}
\hline S1 & \multicolumn{2}{l}{ Proposed Prototype } & \multicolumn{2}{l}{ Existing Prototype } \\
No & Speed(rpm) & Power(watts) & Speed(rpm) & Power(watts) \\
\hline 1 & 36 & 2 & 45 & 0.371 \\
2 & 73 & 8.5 & 55 & 1.19 \\
3 & 109 & 14 & 65 & 2.075 \\
4 & 146 & 15 & 70 & 2.52 \\
\hline
\end{tabular}

Table 2 clearly reveals that the proposed prototype design achieves better performance compared to conventional prototype in term of speed $\mathrm{v} / \mathrm{s}$ power output.

\section{References}

[1] Brown David, "Technical Article: Battery Charging Options for Portable Products", Analogic Tech, 072006

[2] Manwell, J. F., McGowan, J. G., \& Rogers, A. L. (2002). Wind Energy Explained. West Sussex: John Wiley \& Sons Ltd, Pp 39-87 https://doi.org/10.1002/0470846127.

[3] T.S. No, J.E. Kim, J. Moon, S.J. Kim, "Modeling control and simulation of dual rotor wind turbine generator system", Renewable Energy, no. 34, pp. 2124-2132, 2009. https://doi.org/10.1016/j.renene.2009.01.019.

[4] E.M. Farahani, N. Hosseinzadeh, M. Ektesabi, "Comparison of fault-ride-through capability of dual and single-rotor wind turbines", Renewable Energy, no. 48, pp. 473-481, 2012. https://doi.org/10.1016/j.renene.2012.06.010.

[5] .M. Bhutta, N. Hayat, A. Farooq, Z. Ali, S. Jamil, Z. Hussain, "Vertical axis wind turbine - a review of various configurations and design techniques", Renewable and Sustainable Energy Reviews, no. 16, pp. 1926-1939, 2012. https://doi.org/10.1016/j.rser.2011.12.004

[6] N.A. Ahmed, "A novel small scale efficient wind turbine for power generation", Renewable Energy, no. 57, pp. 79-85, 2013. https://doi.org/10.1016/j.renene.2013.01.023.

[7] K. Ishimatsu, K. Kage, T. Okubayashi, "Numerical Simulation for flow fields of Darrieus turbine", Transactions of Japan Society of Mechanical Engineering, vol. 61, pp. 187-192, 1995. https://doi.org/10.1299/kikaib.61.2543.

[8] K. Cheng, Z. Wang, Y. He, G. Yang, "The Comparison of Theoretical Potential Application of Two Types of Wind Turbines in Northern Shaanxi", Power and Energy Engineering Conference (APPEEC); 2012 Asia-Pacific; Shanghai, pp. 1-4, 2012.

[9] N. Gupta, A. Kumar, S. Banerjee and S. Jha, "Magnetically levitated VAWT with closed loop wind speed conditioning guide vanes," 2016 IEEE 1st International Conference on Power Electronics, Intelligent Control and Energy Systems (ICPEICES), Delhi, 2016, pp. 1-5. https://doi.org/10.1109/ICPEICES.2016.7853126.

[10] C T. Carper "Design and construction of vertical axis wind turbine using dual layer vacuum forming.

"dspace.mit.edu/bitstream/handle/1721.1/59899/676694167. Pdf"

[11] J. Fadil, Soedibyo and M. Ashari, "Performance comparison of vertical axis and horizontal axis wind turbines to get optimum power output," 2017 15th International Conference on Quality in Research (QiR): International Symposium on Electrical and Computer Engineering, Nusa Dua, 2017, pp. 429-433. https://doi.org/10.1109/QIR.2017.8168524.

[12] Xiongwei Liu, Lin Wang, Xinzi Tang, "Optimized linearization of chord and twist angle profiles for fixed-pitch fixed-speed wind turbine blades", Renewable Energy, vol. 57, pp. 111-119, 2013. https://doi.org/10.1016/j.renene.2013.01.036.

[13] Dan-Yong Li, Wen-Chuan Cai, Peng Li, Zi-Jun Jia, Yong-Duan Song, Hou-Jin Chen, "Neuro-Adaptive Variable Speed Control of Wind Turbine with Wind Speed Estimation", IEEE Transactions On Industrial Electronics, pp. 7754-7764, 2016. https://doi.org/10.1109/TIE.2016.2591900.

[14] J. L. Achard, G. Maurice, G. Balarac and S. Barre, "Floating vertical axis wind turbine - OWLWIND project," 2017 International Conference on ENERGY and ENVIRONMENT (CIEM), Bucharest, 2017, pp.216-220. https://doi.org/10.1109/CIEM.2017.8120794. 
[15] C. Ma, L. Song and M. Z. Zhang, "Performance study for a novel vertical axis wind turbine based on simulation analysis," 2017 IEEE 14th International Conference on Networking, Sensing and Control (ICNSC), Calabria, 2017, pp.549-554 https://doi.org/10.1109/ICNSC.2017.8000151.

[16] I. Magalhaes Albuquerque and F. F. d. S. Matos, "A Characterization of Vertical Axis Wind Turbines," in IEEE Latin America Transactions, vol. 14, no. 10, pp. 4255-4260, Oct. 2016. https://doi.org/10.1109/TLA.2016.7786302.

[17] B. Hand, A. Cashman and G. Kelly, "A Low-Order Model for Offshore Floating Vertical Axis Wind Turbine Aerodynamics," in IEEE Transactions on Industry Applications, vol. 53, no. 1, pp. 512-520, Jan.-Feb. 2017. https://doi.org/10.1109/TIA.2016.2606088.

[18] C. J. Sudhakar, A. V. Deshpande and D. R. Joshi, "Charge controller for hybrid VAWT and solar PV cells," $20172^{\text {nd }}$ International Conference for Convergence in Technology (I2CT), Mumbai, 2017, pp. 343-347. https://doi.org/10.1109/I2CT.2017.8226148. 